\title{
Farmers and private traders response to rice markets liberalization in Bangladesh
}

\author{
Mohammad Ismail Hossain ${ }^{*}$ and Wim Verbeke*
}

\begin{abstract}
Rice is staple food for Bangladeshi people. Although rice markets were liberalized in 1992, the government continued to intervene in this sector. This study examines the farmers' and private traders' response in liberalized rice marketing system in two regions. 40 farmers and 20 traders were interviewed by using a structural questionnaire for collecting the necessary information. The liberalization of the rice market, in particular, has been embraced more by the private traders then by the farmers. Although there has been a rapid emergence of private traders, the emergence of a vibrant trading sector that would fill the gap left by the state has been slow. The rice market is segmented with the private traders supplying different market circuits. Farmers on the other have not responded positively due to the lack of capital, lack of storage facilities, lack of market information, dominance of intermediaries and low price during the harvest period. Most of the farmers are unwilling to expand their acreage due to the family requirements of other crops. In rural remote areas where the road infrastructure is poor, private sector marketing activities have not yet emerged. Thus government can foster private participation and market integration by improving the road and storage infrastructure. Furthermore, government needs to take measures that strengthen the agricultural price and marketing information system targeted at both farmers and traders.
\end{abstract}

Keywords: liberalization, competition, food policy, market integration, farmers and private traders' response.

\footnotetext{
Submission Date: 18/02/2008_ Revision Date: 11/05/2008_ Acceptance date: 19/05/2008
}

${ }^{*}$ Corresponding author, Assistant Professor, Department of Cooperation \& Marketing, Bangladesh Agricultural University, Mymensingh 2202, Bangladesh. Tel.: +880-01711185763. Fax: +880-91-55810. E-mail: ismailho12 @yahoo.co.in

* Professor, Department of Agricultural Economics, Faculty of Bioscience Engineering, Ghent University, Coupure Links 653, 9000 Gent, Belgium. Tel.: 0032926461 81. Fax: 0032926462 46. E-mail: Wim.Verbeke@UGent.be 


\section{Introduction}

Ensuring food security is one of the major challenges that Bangladesh faces today. Although there are significant achievements in food grain production (food grain production has more than doubled since independence in 1971), food insecurity at both the national and household levels remains a matter of major concern for the government. Currently $40.4 \%$ of the population lives below the food based poverty ${ }^{1}$ line. More than $19 \%$ of the population subsists in extreme poverty (measured by Head Count Rate of hardcore poverty those consume less than 1,805 k.cal/ capita/day) (BBS, 2007). Women and children are especially vulnerable due to their limited access to food. Moreover, large segments of the population periodically undergo the distress of transitory food insecurity caused by drought, floods, cyclones and other natural disasters. Food policy in Bangladesh has undergone major changes over the last decade, moving from a system involving large-scale government intervention in rice and wheat markets to a more market oriented policy, with food grain distribution increasingly targeted to those households most in need. (GOB, 2000, p. 4).

Two implicit assumptions line behind the rice market liberalization in Bangladesh. Firstly, the functions that were carried out by government parastatal organizations previously (i.e. national marketing board), would be taken up automatically by private sector organizations. Prior to liberalization rice price was determined mainly by this board. The board was also responsible to procure rice from domestic markets to build up reasonable stock for supply in the case of a crisis such as flood or cyclone. Secondly, the results of liberalization would enhance the flow of information on local and international prices, supply and demand across the country and make an efficient and integrated market system. As a result of the liberalization food grain production increased but the government aim of food self-sufficiency has not yet been reached. The selfsufficiency for cereals (rice and wheat) in Bangladesh during the period of 1971-72 to 2004-05 varied between $78 \%$ and $96 \%$ (BBS, 2006).

The general consensus on the causes of the food crisis points to the government's prolonged domestic policy failures (Dorosh and Shahabuddin, 2002; Garrett and Chowdhury, 2004). For a long time the Bangladesh government has intervened in all sectors of the economy: in the agricultural sector, in general, and in the rice sub-sector, in particular. Rice is a staple food for Bangladeshi people. It accounts for over $72 \%$ of the total calorie consumption per capita every year (BBS, 2006). From the economic point of view it is the most important commodity in terms of contribution to GDP (13.22\%). More than $90 \%$ of the farmers produce rice (BBS, 2005). $74 \%$ of the total cropped area is allocated to rice cultivation. Furthermore rice accounts for $68 \%$ of the total value added of marketed output of major crops at constant price (BBS, 2005). Due to its importance in both social and political arenas, rice has in the past received a lot of attention both in terms of support and policies. The agricultural policy in general, tended to be biased towards the rice sub-sector, to the extent that agricultural policy became rice policy. Accordingly, changes in

\footnotetext{
${ }^{1}$ Food based poverty line indicates the minimum level of food energy to maintain normal health as the threshold to measure poverty. For Bangladesh, the minimum calorie threshold is $2,122 \mathrm{k.cal} / \mathrm{capita} / \mathrm{day}$ which is known as absolute poverty measured by Direct Calorie Intake method).
} 
rice policies have had important impacts on the entire agricultural sector, agriculture-based industries and consumer welfare.

In the rice marketing system, many actors are involved. The main actors are farmers, traders, creditors, transporters and millers. An effective and efficient marketing channel is that where all the actors play their role and transfer commodities where the transfer is necessary, at the right time, the right price and in the desired form. A well functioning market requires accurate and timely information, a well developed transport network and transportation, adequate financing and storage facilities.

A number of studies in Bangladesh indicate that the liberalization has lead to a fairly competitive trading sector in food grain (Chowdhury et al., 2006; Goletti, 1994). However a number of constraints have limited the participation of traders. These studies reveal further that the majority of entrants into grain markets are those who had previously traded in general merchandise and had branched into grain trading upon liberalization of the market. This paper attempts to investigate the characteristics of the major actors in the liberalized rice marketing system and identifies the constraints that may be restricting private sector participation.

\section{Methodology}

In order to meet the goals of observing the response of private market participants to rice market liberalization, determining the emerging networks and analyzing market efficiency, a field survey was conducted in one surplus and one deficit region of the country. The survey design proceeded from the belief that traders' responses to rice market liberalization will be more beneficial in those regions of Bangladesh with the highest potential for producing marketable surpluses of rice and less beneficial in those areas with the lowest potential. The Gazipur district from the Dhaka division and the Rangpur district from the Rajshahi division were selected. They are examples of deficit and surplus areas respectively. Within each district one Upazila ${ }^{2}$ was selected, Sreepur for Gazipur and Mithapukur for Rangpur. From Sreepur Upazila, 21 farmers (5 large, 8 medium and 8 small farm holdings) and from Mithapukur Upazila, 19 farmers (5 large farmers, 7 medium farmers and 7 small farmers) were selected for collecting the necessary information. From each of the Upazila, 10 traders were selected. The primary data were collected from farmers and traders using two separate questionnaires. The trader survey sought information from private traders on strategies for sales and acquisition of rice stocks, pricing strategies, seasonality of sales and purchases and investment strategies. The farmer survey sought information on farmers' response to rice market liberalization.

\footnotetext{
${ }^{2}$ The districts of Bangladesh are divided into subdistricts, or Upazilas. The upazilas are the lowest level of administrative government in Bangladesh.
} 


\section{Results and discussion}

\subsection{Farmers response to market liberalization-farmer characteristics}

The farmers covered in this study were large ${ }^{3}$, medium ${ }^{4}$ and small ${ }^{5}$ farm holdings who depend on agriculture for their livelihood. Table 1 shows the different characteristics of the sample farmers in two regions. All the farmers in the sample were male as in Ismail (1999), and Tasnoova $\&$ Iwamoto (2006). The wife in rural Bangladesh takes care of the children and is responsible for boiling, drying, husking the rice.

Half of the household heads were below 40 years, which also is the same as Ismail (2005). $45 \%$ were between 41 and 60 years old and only 5\% above 60 years. The age distribution for Sreepur Upazila was 43\%, 52\% and 5\% respectively. For Mithapukur, the corresponding age distribution was 58\%, 37\% and 5\% respectively. In Sreepur, 33\% and 38\% of farmers are aged 3140 years and $41-50$ years whereas in Mithapukur these were $40 \%$ and 30\% respectively. In both regions, small and medium farmers were relatively youthful. There were no differences in the age distribution of holding size.

Table 1

Characteristics of farmers $(n=40)$

\begin{tabular}{|c|c|c|c|c|c|c|c|c|c|}
\hline \multirow{2}{*}{ Characteristics } & \multicolumn{4}{|c|}{ Sreepur } & \multicolumn{4}{|c|}{ Mithapukur } & \multirow{2}{*}{ Overall } \\
\hline & Small & Medium & Large & Total & Small & Medium & Large & Total & \\
\hline \multicolumn{10}{|l|}{ Sex } \\
\hline Total Number & 8.0 & 7.0 & 5.0 & 20.0 & 8.0 & 7.0 & 5.0 & 20.0 & 40.0 \\
\hline$\%$ male & 100.0 & 100.0 & 100.0 & 100.0 & 100.0 & 100.0 & 100.0 & 100.0 & 100.0 \\
\hline Age distribution & \multicolumn{9}{|c|}{ Percentage of farmers } \\
\hline $20-30$ & - & 25.0 & - & 9.5 & 28.6 & - & - & 10.5 & 10 \\
\hline $31-40$ & 37.5 & 25.0 & 40.0 & 33.3 & 57.1 & 28.6 & 60.0 & 47.4 & 40 \\
\hline $41-50$ & 25.0 & 50.0 & 40.0 & 38.1 & 14.3 & 28.6 & 20.0 & 21.1 & 30 \\
\hline $51-60$ & 25.0 & - & 20.0 & 14.3 & - & 28.6 & 20.0 & 15.8 & 15 \\
\hline 61-above & 12.5 & - & - & 4.8 & - & 14.3 & - & 5.3 & 5 \\
\hline \multicolumn{10}{|c|}{ Education $(\%)$} \\
\hline No education & 50.0 & 12.5 & - & 23.8 & 28.6 & 28.6 & 20.0 & 26.3 & 25 \\
\hline Primary & 25.0 & 50.0 & 60.0 & 42.9 & 28.6 & 28.6 & - & 21.1 & 32.5 \\
\hline Secondary & 12.5 & 37.5 & 20.0 & 23.8 & 42.9 & 28.6 & 60.0 & 42.1 & 32.5 \\
\hline Collage and above & 12.5 & - & 20.0 & 9.5 & - & 14.3 & 20.0 & 10.5 & 10 \\
\hline
\end{tabular}

Source: Field survey data (2007)

\footnotetext{
${ }^{3}$ Large farmers are those who hold 7.50 acres or more acres of land.

${ }^{4}$ Medium farmers are those who hold 2.50 - 7.49 acres.

${ }^{5}$ Small farmers are those who hold $1-2.49$ acres.
} 
Table 1 also shows that $32.5 \%$ of the sample farmers had attained primary education and secondary education. $25 \%$ of the farmers had no formal education and $10 \%$ of farmers had college and higher education. There was no deviation by farm size or region from overall figures. National literacy was $38.1 \%$, which was second lowest of the Asian countries. This figure appears in Handbook of Agricultural Statistics (2005), Ismail (1999) and Tasnoova \& Iwamoto (2006). Our survey shows that more than half $(57.5 \%)$ of the sample farmers had no education or simply primary education, which limits their ability to receive and process agricultural information to raise farm productivity.

\subsection{Income of the farmers}

The sources of the income of the farmers are agriculture, business, service, labor and other (mainly pulling of rickshaw and van). The total annual income of the small, medium and large farm households in Sreepur was Tk. 73,013, Tk. 149,225 and Tk. 328,333. In Mithapukur it was Tk. 73,181, Tk. 149,225 and Tk. 226,860 respectively ${ }^{6}$. In the studied areas the small farmers had diversified income sources and renting out labor was the main income earning activity. On the other hand, large farmers concentrate on agriculture, business and service with agriculture as the main income source. Medium farmers mainly depended on agriculture and business (Tasnoova and Iwamoto, 2006).

Table 2

Annual incomes (Taka) of the sample farmers $(n=40)$

\begin{tabular}{|c|c|c|c|c|c|c|}
\hline Farm categories & Agriculture & Business & Service & Labor & Other & Total \\
\hline \multicolumn{7}{|c|}{ Small farmers $(n=16)$} \\
\hline Sreepur & 12,363 & 20,400 & 15,000 & 22,000 & 3,250 & 73,013 \\
\hline Mitapuku & 16,914 & 16,600 & 14,000 & 23,000 & 2,667 & 73,181 \\
\hline \multicolumn{7}{|c|}{ Medium farmers $(n=14)$} \\
\hline Sreepur & 48,225 & 50,000 & 37,500 & 0 & 13,500 & 149,225 \\
\hline Mitapuku & 41,703 & 23,400 & 27,000 & 5,000 & 51,640 & 148,743 \\
\hline \multicolumn{7}{|c|}{ Large farmers $(\mathrm{n}=10)$} \\
\hline Sreepur & 171,000 & 42,333 & 115,000 & 0 & 0 & 328,333 \\
\hline Mitapuku & 93,360 & 68,500 & 65,000 & 0 & 0 & 226,860 \\
\hline
\end{tabular}

Source: Field survey data (2007)

\footnotetext{
${ }^{6}$ One dollar is worth Taka 68.28 (Last consulted date: 22/01/ 2008 on Bangladesh Bank website, a central Bank of Bangladesh, http://www.bangladesh-bank.org).
} 


\subsection{Farming experience and activities}

In both areas, the large farmers had more farming experience compared to small and medium farmers. The major crops grown in the two areas are rice, vegetables, wheat and maize. Minor crops grown include fruits, sugarcane, bottlegourd and groundnut. In spite of liberalization, rice still dominates in the two regions. In fact when farmers were asked to rank the crops they grow in order of importance of income earned, rice ranked first followed by vegetables, wheat and maize (Table 3).

Table 3

Crop production experience and preference by rank in Sreepur and Mithapukur

\begin{tabular}{|c|c|c|c|c|c|c|}
\hline & \multirow{2}{*}{ Farming experience (years) } & \multicolumn{5}{|c|}{ Crop rank } \\
\hline & & 1 & 2 & 3 & 4 & 5 \\
\hline \multicolumn{7}{|c|}{ Sreepur $(n=20)$} \\
\hline Small & 14 & Rice & Vegetables & Fruits & Sugarcane & Wheat \\
\hline Medium & 13 & Rice & Groundnut & Fruits & Vegetables & Bottlegourd \\
\hline Large & 22 & Rice & Vegetables & Fruits & Groundnut & Sugarcane \\
\hline \multicolumn{7}{|c|}{ Mithapukur $(\mathrm{n}=20)$} \\
\hline Small & 10 & Rice & Vegetables & Fruits & Wheat & Maize \\
\hline Medium & 12 & Rice & Wheat & Vegetables & Sugarcane & Fruits \\
\hline Large & 19 & Rice & Maize & Wheat & Vegetables & Sugarcane \\
\hline
\end{tabular}

Note: Rank 1 most preferred crop and rank 5 less preferred.

Source: Field survey data (2007)

\subsection{Change in cropping pattern and reasons of change in cropping pattern}

In the last five years, respectively $79 \%$ and $71 \%$ of the farmers in Sreepur and Mithapukur regions changed their cropping pattern (Table 4). All of the large farmers in both areas changed their cropping pattern but medium and small farmers changed relatively less. The main reason for changing cropping pattern was for the profitability of the crop grown followed by the family needs, then maintaining soil fertility, and lastly shortage of irrigation water. The majority of the small farmers changed their cropping pattern due to family needs for different crops. 
Table 4

Percentage of farmers change in cropping pattern and reasons of change

\begin{tabular}{|c|c|c|c|c|c|c|}
\hline & \multirow[b]{2}{*}{ Change (\%) } & \multirow[b]{2}{*}{ Not change $(\%)$} & \multicolumn{4}{|c|}{ Reason of change in cropping pattern ( $\%$ of farmers) } \\
\hline & & & $\begin{array}{l}\text { According to } \\
\text { family need }\end{array}$ & $\begin{array}{l}\text { Maintain } \\
\text { soil fertility }\end{array}$ & $\begin{array}{c}\text { For } \\
\text { profitability }\end{array}$ & $\begin{array}{c}\text { Shortage of } \\
\text { irrigation } \\
\text { water } \\
\end{array}$ \\
\hline \multicolumn{7}{|c|}{ Sreepur $(n=20)$} \\
\hline Small & 50 & 50 & 80 & & & 20 \\
\hline Medium & 87.5 & 12.5 & & 10 & 75 & 15 \\
\hline Large & 100 & 0 & & 5 & 90 & 5 \\
\hline \multicolumn{7}{|c|}{ Mithapukur $(\mathrm{n}=20)$} \\
\hline Small & 85.7 & 14.3 & 25 & 25 & 50 & \\
\hline Medium & 28.6 & 71.4 & 45 & & 65 & \\
\hline Large & 100 & 0 & & 10 & 85 & 5 \\
\hline
\end{tabular}

Source: Field survey data (2007)

\subsection{Rice production, sales and price received by the farmers}

The large and medium farmers produce the bulk of marketed rice in the two regions. As already mentioned Mithapukur is surplus area and Sreepur is deficit region. The study also confirms this. Large farmers in Mithapukur area marketed twice as much rice as those in the Sreepur region (Table 5). Large farmers are able to get better prices than medium and small farmers (Table 6). This can be explained by the sales strategy of the different farm categories. Small and medium farmers sell their output immediately after harvest whereas large farmers sell their product during the lean period when market prices reach high levels.

Table 5

Average rice production and sales by farmers (quintal)

\begin{tabular}{l|c|c|c|c|c|c}
\hline & \multicolumn{3}{|c|}{ Sreepur $(\mathrm{n}=20)$} & \multicolumn{3}{c}{ Mithapukur $(\mathrm{n}=20)$} \\
\cline { 2 - 7 } & Small & Medium & Large & Small & Medium & Large \\
\hline \hline Production of rice & 10.6 & 37.6 & 66.9 & 10.1 & 38.1 & 106.9 \\
Sales of rice & 4.3 & 16.2 & 40.7 & 4.9 & 20.1 & 81.0 \\
\hline
\end{tabular}

Source: Field survey data (2007) 
Table 6

Average rice price (Tk./quintal) received by farmers

\begin{tabular}{c|c|c}
\hline Farm categories & 2005 & 2006 \\
\hline \hline Small $(\mathrm{n}=16)$ & 1112.5 & 1287.5 \\
Medium $(\mathrm{n}=14)$ & 1127.5 & 1297.5 \\
Large $(\mathrm{n}=10)$ & 1150 & 1305 \\
\hline
\end{tabular}

Source: Field survey data (2007)

In Sreepur Upazila, Farias ${ }^{7}$ and Beparis ${ }^{8}$ are the main buyers of rice, but this area is closest to the central market and capital city of Dhaka (approximately $30 \mathrm{~km}$ ) and on average the number of the traders is also small (below 10 persons). Whereas in Mithapukur the number of traders are 17 and some of them are large traders; e.g. Aratdars ${ }^{9}$ who comes from the central market and other neighboring districts (Table 7). This means that the number of middlemen and the volume of businesses were small in Sreepur.

Table 7

Name of the buyers, their location and numbers

\begin{tabular}{c|c|c|c}
\hline Region & Name of the buyers & Location & Numbers \\
\hline \hline Sreepur $(\mathrm{n}=20)$ & Faria, Beparis & Local & 10 \\
Mithapukur $(\mathrm{n}=20)$ & Beparis, Aratdars & Local, neighboring districts and Dhaka & 17 \\
\hline
\end{tabular}

Source: Field survey data (2007)

Due to the lack of transport and the nature of the road infrastructure most farmers are only able to sell their crops within their localities as opposed to other districts where they could sell at higher prices (Table 8).

\footnotetext{
${ }^{7}$ Farias are the middlemen who buy comparatively lower quantity of volume crops directly from the farmers either at the farmyard or in the primary markets. They are mostly seasonal and local traders. Some had other occupations. They sell crops to the Bapari, and sometimes to millers.

${ }^{8}$ Beparis make their purchase from the farmers or Farias and bring crops from the primary markets to secondary markets and sell them to millers and Aratdars. Their volume of business is larger than that of Farias and possesses more capital.

${ }^{9}$ They are the secondary middlemen in rice trade. They are commission agents who have fixed establishment in the market. Their scale of business is larger than that of Faria and Bepari. Aratdars' remuneration is at a fixed rate which he charges either the buyer or the seller depending on the condition of supply and demand. He has his own staff for loading, unloading, packing and weighing the crop.
} 
Table 8

Can you easily sell produce (percentage)?

\begin{tabular}{c|c|c|c|c}
\hline \multirow{2}{*}{ Region } & \multicolumn{2}{|c|}{ Within district } & \multicolumn{2}{c}{ Outside district } \\
\cline { 2 - 5 } & Yes & No & Yes & No \\
\hline \hline Sreepur (n=20) & 85.7 & 14.3 & 90.5 & 9.5 \\
Mithapukur (n=20) & 68.4 & 31.6 & 10.5 & 89.5 \\
\hline
\end{tabular}

Source: Field survey data (2007)

\subsection{On-farm storage and market accessibility}

A better market information system in itself is not useful unless farmers understand the meaning conveyed in the information and are able to utilize it in their decision making process. In Bangladesh for instance farmers were not taking advantage of price variations between markets and market information due to a lack of on-farm storage as in indicated in Table 9 . Nearly $35 \%$ of the farmers did not practice on-farm storage and when they use on-farm storage it is for the reason of family requirement, not for reaping the benefit of higher prices. The majority of the farmers $(90 \%)$ reported they have no farm marketing group and those who are engaged with a group state that this group is not benefiting them.

Table 9

Percentage of farmers practicing on farm storage and form of marketing group

\begin{tabular}{c|c|c|c|c}
\hline \multirow{2}{*}{ Region } & \multicolumn{2}{|c|}{ On farm storage } & \multicolumn{2}{c}{ Form marketing group } \\
\cline { 2 - 5 } & Yes & No & Yes & No \\
\hline \hline Sreepur $(\mathrm{n}=20)$ & 61.9 & 38.1 & 9.5 & 90.5 \\
Mithapukur $(\mathrm{n}=20)$ & 68.4 & 31.6 & 10.5 & 89.5 \\
Total & 65.15 & 34.85 & 10 & 90 \\
\hline
\end{tabular}

Source: Field survey data(2007)

Farmers argued that during the last year rice prices have been very attractive but also that input prices were high. As a result, only one third of the farmers expanded rice cultivation area (Table 10). 
Table 10

Percentage of farmers response on last year price and acreage expand

\begin{tabular}{c|c|c|c|c|c}
\hline \multirow{2}{*}{ Region } & \multicolumn{3}{|c|}{ Pricing } & \multicolumn{2}{c}{ Acreage expand } \\
\cline { 2 - 6 } & Very attractive & Attractive & Indifferent & Yes & No \\
\hline \hline Sreepur (n=20) & 33.3 & 57.1 & 9.5 & 33.3 & 66.7 \\
Mithapukur (n=20) & 21.1 & 63.2 & 15.8 & 26.3 & 73.7 \\
\hline
\end{tabular}

Source: Field survey data (2007)

The poor state of feeder roads has also constrained the response of the farmers to rice market liberalization. Most roads in the survey areas are in a deplorable state and are usually inaccessible during the rainy season. For the majority (71\%) of the farmers in Sreepur (closest to the urban area), roads are very good and the nearest bus station is $8 \mathrm{~km}$. On the other hand, in Mithapukur (rural area), over half of the farmers (53\%) claimed that roads are not so bad as in other rural areas. Good roads facilitate a connection to the road network (Kutcha) and the closest distance of bus stop is an average of $21 \mathrm{~km}$ (Table 11). Due to the bad state of feeder roads and perhaps the low incomes, the most common mode of transport found was van and ox-carts.

Table 11

Condition of road infrastructure $(\%)$ and distance from closest urban area $(\mathrm{km})$

\begin{tabular}{|c|c|c|c|c|c|}
\hline \multirow{2}{*}{ Region } & \multicolumn{4}{|c|}{ Infrastructure } & \multirow[t]{2}{*}{ Distance } \\
\hline & Very good & Good & Indifferent & Not so bad & \\
\hline Sreepur & 71.4 & 28.6 & - & - & 8 \\
\hline Mithapukur & - & 36.8 & 10.5 & 52.6 & 21 \\
\hline
\end{tabular}

Source: Field survey data (2007)

The Department of Agricultural Marketing (DAM) publishes weekly bulletins on input and product price information. This information also is broadcast on radios. But the market price information provided by the DAM deviate from actual price. Farmers in the study areas had limited access to market information, which would have enabled them to make critical decisions regarding to which crops to grow, where and to whom to sell the crops. Only one third of the sample farmers in the two areas reported receiving price information and the majority (75\%) received this information from discussions with other farmers (Table 12). 
Table 12

Percentage of farmers receive price information

\begin{tabular}{c|c|c}
\hline Region & Yes & No \\
\hline Sreepur $(\mathrm{n}=20)$ & 28.6 & 71.4 \\
Mithapukur $(\mathrm{n}=20)$ & 26.3 & 73.7 \\
\hline
\end{tabular}

Source: Field survey data (2007)

\subsection{Constraints to performance of the farmers}

A number of problems has surfaced following the liberalization of crop marketing which, if not addressed, is likely to depress the positive response from farmers. $83 \%$ of the farmers reported selling their rice at a lower price adjusted for inflation than before liberalization. This is mainly because they need immediate cash to cover family expenses. About $76 \%$ of the farmers complained that they did not receive institutional loans and for that reason they had to borrow money from the moneylender at high interest rate. $75 \%$ of the farmers claimed that they have very limited information about market demand, supply, and prices of products. They usually sold their product without any prior knowledge of market price. The communication networks of the study areas (especially in Mithapukur) were not well developed for the transfer of agricultural products from the producers to the consumers. About $68 \%$ of the farmers reported that they could not benefit from the higher prices prevailing at distant markets due to poor communication and transportation facilities. Intermediaries in the studied markets were small in numbers but organized. For these reasons, $63 \%$ of the farmers were compelled to sell their product at a lower price than consumers pay due to dominance of intermediaries with monopoly power and the high cost of distribution to consumers. The storage facilities of the study area were not good. $55 \%$ of the farmers complained about the storage problem. The farmers generally used separate Kutcha Gola ${ }^{10}$ all of which were rudimentary and unscientifically prepared. Lack of market facilities (43\%) and high market tolls (39\%) were also problems for the farmers (Table 13). The market tolls (charged to cover the cost for cleaning and government tax) were collected by eye estimation of the volume of rice marketed by the farmers and varied from market to market. In the study area, at the market place there were no sheds to protect the farmers and their produce from the weather and the farmers had to sit in the open to sell their product.

\footnotetext{
${ }^{10} \mathrm{~A}$ local term meaning storing rice in an unscientific way at home.
} 
Table 13

Problems faced by farmers $(\%)$

\begin{tabular}{l|c|c|c|c|c|c|c|c|c|c}
\hline \multirow{2}{*}{ Problems } & \multicolumn{4}{|c|}{ Sreepur(n=20) } & \multicolumn{3}{c|}{ Mithapukur(n=20) } & \multirow{2}{*}{ Overall } \\
\cline { 2 - 8 } & Small & Medium & Large & All & Small & Medium & Large & All & \\
\hline \hline Lack of capital & 90.0 & 65.0 & 45.0 & 66.7 & 100.0 & 88.0 & 69.0 & 85.7 & 76.2 \\
Poor communication and transportation & 55.0 & 48.0 & 41.0 & 48.0 & 88.0 & 95.0 & 80.0 & 87.7 & 67.8 \\
Lack of adequate storage & 40.0 & 37.0 & 79.0 & 52.0 & 55.0 & 52.0 & 67.0 & 58.0 & 55.0 \\
Lack of market information & 62.0 & 85.0 & 72.0 & 73.0 & 67.0 & 80.0 & 84.0 & 77.0 & 75.0 \\
Low market price at harvest period & 78.0 & 70.0 & 73.0 & 73.7 & 90.0 & 98.0 & 90.0 & 92.7 & 83.2 \\
Dominance of intermediaries & 60.0 & 68.0 & 55.0 & 61.0 & 65.0 & 72.0 & 60.0 & 65.7 & 63.3 \\
High market tolls & 45.0 & 40.0 & 37.0 & 40.7 & 45.0 & 38.0 & 30.0 & 37.7 & 39.2 \\
Lack of market facilities & 47.0 & 43.0 & 40.0 & 43.3 & 43.0 & 37.0 & 45.0 & 41.7 & 42.5 \\
\hline
\end{tabular}

Source: Field survey data (2007)

Farmers suggested that the price of rice should be fixed by the government at harvest time and institutional credit facilities should be made available at easy terms and conditions to increase the production of rice.

Farmers were asked to what degree they understood the liberalized crop marketing system (Table 14). The majority of the farmers (84\%) who responded to this question had little (42.8\%) or no understanding $(41.5 \%)$ while only $12 \%$ understood the new marketing system fairly well and $3 \%$ understood it very well. Of those who reported that they understood the liberalized marketing system $88 \%$ of them agree that liberalized system raised prices but only $37 \%$ reported that this new system has created opportunities for them. This suggests that farmers do not have a clear and well informed understanding of the implications of market liberalization. 
Table 14

Percentage distribution of the degree to which farmers understand the implications of market liberalization

\begin{tabular}{c|c|c|c|c}
\hline & Not at all & Just a little bit & Fairly well & Very well \\
\hline \hline Sreepur(n=20) & 23.8 & 51.4 & 18.1 & 6.7 \\
Small & 42.9 & 57.1 & - & - \\
Medium & 28.6 & 57.1 & 14.3 & 20.0 \\
Large & - & 40.0 & 40.0 & - \\
Mithapukur(n=20) & 59.2 & 34.2 & 6.7 & - \\
Small & 50.0 & 50.0 & - & - \\
Medium & 87.5 & 12.5 & - & 3.3 \\
Large & 40.0 & 40.0 & 20.0 & 12.4 \\
Sample & 41.5 & 42.8 & & \\
\hline
\end{tabular}

Source: Field survey data (2007)

\section{Results on traders' response to market liberalization}

\subsection{Characteristics of traders and traders' entry into rice marketing}

Table 15 presents the main characteristics of the traders interviewed. The general picture that emerged is that of a market dominated by middle aged traders $(60 \%)$ all of them were men who had completed secondary education (40\%). The majority (65\%) had entered the rice trading after liberalization, indicating that it become easy to enter the market once it was liberalized. Although rice was the dominant crop traded, traders also engaged in other activities i.e. rice trading and farming (40\%) and rice trading and milling (15\%). To take into account the variation in size the analysis that follows is based on a division of the sample into two main categories: large and small traders. Small traders are composed of Beparis and retailers and large traders are the wholesalers and millers. Small traders were those who handled less than 90 quintals of rice in one marketing season, large traders handled above 90 quintals. 
Table 15

Characteristics of traders $(n=20)$

\begin{tabular}{|c|c|c|c|c|c|}
\hline \multirow[b]{2}{*}{ Characteristics } & \multicolumn{2}{|c|}{ Sreepur } & \multicolumn{2}{|c|}{ Mithapukur } & \multirow[b]{2}{*}{ Total } \\
\hline & $\begin{array}{c}\text { Small traders } \\
\text { (Bepari \& } \\
\text { retailer) } \\
\end{array}$ & $\begin{array}{c}\text { Large traders } \\
\text { (Wholesaler \& } \\
\text { Miller) }\end{array}$ & $\begin{array}{c}\text { Small traders } \\
\text { (Bepari \& retailer) }\end{array}$ & $\begin{array}{c}\text { Large traders } \\
\text { (Wholesaler \& } \\
\text { Miller) } \\
\end{array}$ & \\
\hline Number of respondents & 7 & 3 & 6 & 4 & 20 \\
\hline $\begin{array}{c}\text { Age between } 30-40 \\
\text { years }\end{array}$ & $4(57.1)$ & $2(66.7)$ & $1(16.7)$ & - & $7(35.0)$ \\
\hline $\begin{array}{c}\text { Age between } 41-50 \\
\text { years }\end{array}$ & $3(42.9)$ & $1(33.3)$ & $4(66.7)$ & $4(100.0)$ & $12(60.0)$ \\
\hline $\begin{array}{l}\text { Age between 51-60 } \\
\text { years }\end{array}$ & - & - & $1(16.7)$ & - & $1(5.0)$ \\
\hline$\%$ Male & $7(100.0)$ & $3(100.0)$ & $6(100.0)$ & $4(100.0)$ & $20(100.0)$ \\
\hline $\begin{array}{l}\% \text { that have no formal } \\
\text { education }\end{array}$ & $2(28.6)$ & - & $1(16.7)$ & - & $3(15.0)$ \\
\hline $\begin{array}{l}\% \text { that finished primary } \\
\text { education }\end{array}$ & $3(42.9)$ & - & $4(66.7)$ & - & $7(35.0)$ \\
\hline $\begin{array}{c}\text { \% that finished } \\
\text { secondary education }\end{array}$ & $2(28.6)$ & $1(33.3)$ & $1(16.7)$ & $4(100.0)$ & $8(40.0)$ \\
\hline $\begin{array}{l}\% \text { that finished } \\
\text { collage/university } \\
\text { education }\end{array}$ & - & $2(66.7)$ & - & - & $2(10.0)$ \\
\hline $\begin{array}{l}\text { \% that entered rice } \\
\text { trading before } 1992\end{array}$ & $2(28.6)$ & $1(33.3)$ & $2(33.3)$ & $2(50.0)$ & $7(35.0)$ \\
\hline $\begin{array}{l}\% \text { that entered rice } \\
\text { trading after } 1992\end{array}$ & $5(71.4)$ & $2(66.7)$ & $4(66.7)$ & $2(50.0)$ & $13(65.0)$ \\
\hline$\%$ trading in rice only & $2(28.6)$ & $2(66.7)$ & $1(16.7)$ & $2(50.0)$ & $7(35.0)$ \\
\hline $\begin{array}{l}\% \text { trading in rice and } \\
\text { farming }\end{array}$ & $4(57.1)$ & - & $4(66.7)$ & - & $8(40.0)$ \\
\hline $\begin{array}{c}\% \text { trading in rice and } \\
\text { milling }\end{array}$ & - & $1(33.3)$ & - & $2(50.0)$ & $3(15.0)$ \\
\hline $\begin{array}{l}\% \text { trading in rice and } \\
\text { other activities }\end{array}$ & $1(14.3)$ & - & $1(16.7)$ & - & $2(10.0)$ \\
\hline
\end{tabular}

Note: Figure in the parentheses indicates percentage.

Source: Field survey data (2007)

It appears that the main attraction to rice trading was the perceived profitability of rice and the apparent existence of rice markets (Table 16). 
Table 16

Reasons for starting rice trading $(\%)(n=20)$

\begin{tabular}{|c|c|c|c|c|}
\hline & Availability of market & Number of clients & Storage facilities & Profitability \\
\hline \multicolumn{5}{|c|}{ Small traders-Sreepur } \\
\hline V. Considered & & 28.6 & & \\
\hline Considered & 85.7 & 28.6 & & 100.0 \\
\hline Indifferent & & 42.9 & 14.3 & \\
\hline Less considered & 14.3 & & 28.6 & \\
\hline Not considered & & & 57.1 & \\
\hline \multicolumn{5}{|c|}{ Large traders-Sreepur } \\
\hline V.Considered & 33.3 & 33.3 & & 33.3 \\
\hline Considered & 66.7 & 33.3 & & 66.7 \\
\hline Indifferent & & 33.3 & 100.0 & \\
\hline \multicolumn{5}{|c|}{ Small traders-Mithapukur } \\
\hline V.Considered & 16.7 & 16.7 & & \\
\hline Considered & 66.7 & 66.7 & & 100.0 \\
\hline Indifferent & 16.7 & 16.7 & 33.3 & \\
\hline Less considered & & & 16.7 & \\
\hline Not considered & & & 50.0 & \\
\hline \multicolumn{5}{|c|}{ Large traders-Mithapukur } \\
\hline V. Considered & 50.0 & 25.0 & & 25.0 \\
\hline Considered & 50.0 & 75.0 & 25.0 & 75.0 \\
\hline Indifferent & & & 75.0 & \\
\hline
\end{tabular}

Source: Field survey data (2007)

\subsection{Sources and destination of rice}

The responses from traders indicated that there were no hard and fast rules about where and how they obtained their crops. Small traders in studied areas obtained their rice very often in the market and large traders collected both within the studied markets and at neighboring districts or neighboring markets (Table 17). The majority $(86 \%)$ of the small traders in Sreepur very often obtained their rice from within the markets and often from neighboring markets. $14 \%$ of the small traders in Sreepur sometimes obtained rice from neighboring districts and rest of them never obtained from neighboring districts. But in Mithapukur, all of the sampled small traders very often 
collected rice from within markets and $83 \%$ of them often purchased from neighboring markets. Large farmers in both areas very often obtained rice from within markets and often from neighboring markets.

Table 17

Sources of rice for trading $(\%)(n=20)$

\begin{tabular}{|c|c|c|c|}
\hline & Within the market & Neighboring market & Neighboring districts \\
\hline \multicolumn{4}{|c|}{ Small traders-Sreepur } \\
\hline Very often & 85.7 & & \\
\hline Often & 14.3 & 100.0 & \\
\hline Sometime & & & 14.3 \\
\hline Never & & & 85.7 \\
\hline \multicolumn{4}{|c|}{ Large trader-Sreepur } \\
\hline Very often & 66.7 & & 33.3 \\
\hline Often & 33.3 & 100.0 & 33.3 \\
\hline Indifferent & & & 33.3 \\
\hline \multicolumn{4}{|c|}{ Small trader-Mithapukur } \\
\hline Very often & 100.0 & 16.7 & \\
\hline Often & & 83.3 & \\
\hline Sometime & & & 33.3 \\
\hline Never & & & 66.7 \\
\hline \multicolumn{4}{|c|}{ Large trader-Mithapukur } \\
\hline Very often & 100.0 & & \\
\hline Often & & 100.0 & \\
\hline Indifferent & & & 25.0 \\
\hline Sometime & & & 75.0 \\
\hline
\end{tabular}

Source: Field survey data (2007)

The destination of the rice, on the other hand, was mostly outside of the districts. Rice was sold mostly to consumers (65\%) while the reminder was sold to retailers (Table 18). Interesting here is that small traders in both areas supplied the bulk of rice to consumers while large traders supplied exclusively to the retailers. These results suggested that the traders are segmented in their trade. It is also indicated that in general traders are buying rice from within the markets and neighboring markets and sell it to deficit markets. Thus the flow of crops traded is from surplus 
regions to deficit regions.

Table 18

Percentage of purchase from and selling to of rice in different sources $(\%)(n=20)$

\begin{tabular}{l|c|c|c|c|c|c}
\hline & \multicolumn{3}{|c|}{ Purchase from } & \multicolumn{3}{c}{ Sell to } \\
\cline { 2 - 7 } & Sreepur & Mithapukur & Total & Sreepur & Mithapukur & Total \\
\hline \hline Farmer & 20 & 10 & 15 & & & \\
\hline Faria/Bepari & & 10 & 5 & & & \\
\hline Wholesaler & 40 & 40 & 40 & & & \\
Miller & 40 & 40 & 40 & & & \\
Retailer & & & & 30 & 40 & 35 \\
Consumer & & & & 70 & 60 & 65 \\
\hline
\end{tabular}

Source: Field survey data (2007)

In order to determine whether traders were engaging in speculative buying/selling, they were asked to indicate the strategies they employ in buying and selling rice. Table 19 indicates that $65 \%$ of the traders buy at harvest time and $40 \%$ hold until price increases indicating their speculative nature. There was no difference between small traders and large traders in the two regions. $10 \%$ and $5 \%$ of the traders reported that they had no buying and selling strategies.

Table 19

Buying and selling strategies of rice by traders $(\%)(n=20)$

\begin{tabular}{|c|c|c|c|c|c|}
\hline & \multicolumn{2}{|c|}{ Sreepur $(n=10)$} & \multicolumn{2}{|c|}{ Mithapukur $(\mathrm{n}=10)$} & \multirow{2}{*}{ Total } \\
\hline & Small traders & Large traders & Small traders & Large traders & \\
\hline \multicolumn{6}{|c|}{ Buying strategies } \\
\hline Harvest time & 71.4 & 33.3 & 66.7 & 75.0 & 65.0 \\
\hline $\begin{array}{c}\text { Progressive buying over the whole } \\
\text { year }\end{array}$ & 14.3 & 66.7 & 16.7 & 25.0 & 25.0 \\
\hline No specific strategy & 14.3 & & 16.7 & & 10.0 \\
\hline \multicolumn{6}{|c|}{ Selling strategies } \\
\hline No alternative buyers & 42.9 & & 50.0 & & 30.0 \\
\hline The buyer offered a higher price & 28.6 & 33.3 & 16.7 & 25.0 & 25.0 \\
\hline Hold until price increase & 28.6 & 66.7 & 16.7 & 75.0 & 40.0 \\
\hline No strategy & & & 16.7 & & 5.0 \\
\hline
\end{tabular}

Source: Field survey data (2007) 
In both areas, a majority ( $80 \%$ ) of the traders had no storage facilities outside of their homes and they also did not rent storage (Table 20). Traders use their houses for storage.

Table 20

Information of own storage facilities and rent of storage (\%)

\begin{tabular}{l|c|c|c|c}
\hline \multirow{2}{*}{ Region } & \multicolumn{2}{|c|}{ Own storage } & \multicolumn{2}{c}{ Rent of storage } \\
\cline { 2 - 5 } & Yes & No & Yes & No \\
\hline \hline Sreepur $(\mathrm{n}=10)$ & 20 & 80 & - & 100 \\
Mithapukur $(\mathrm{n}=10)$ & 20 & 80 & - & 100 \\
\hline
\end{tabular}

Source: Field survey data (2007)

Large traders in Mithapukur upazila received higher margins compared to the others. On an average, in the study regions, buying price was Tk. 1103 and selling price was 1129 which was reasonable considering transportation costs (Table 21).

Table 21

Buying and selling price of rice for different market participants (Tk./quintal)

\begin{tabular}{c|c|c}
\hline & Buying price & Selling price \\
\hline \hline Small traders-Sreepur $(\mathrm{n}=7)$ & 1111.1 & 1125.8 \\
Large traders-Sreepur $(\mathrm{n}=3)$ & 1095.8 & 1120.8 \\
Small traders-Mithapukur $(\mathrm{n}=6)$ & 1106.9 & 1131.3 \\
Large traders-Mithapukur $(\mathrm{n}=4)$ & 1098.8 & 1137.5 \\
Total & 1103.1 & 1128.9 \\
\hline
\end{tabular}

Source: Field survey data (2007)

\subsection{Constraints}

Among the major problems faced by the traders, lack of sufficient funds $(73 \%)$ was the most pressing followed by lack of means of transport (52\%) and lack of market information (46\%). Among the large traders the milling problem (such as scarcity of spare parts, bad weather, lack of temporary labour in season, etc.) was the most pressing while among the small traders lack of sufficient funds was the most pressing (Table 22). 
Table 22

Constraints faced by the traders $(\%)$

\begin{tabular}{c|c|c|c|c|c}
\hline \multirow{2}{*}{ Problems } & \multicolumn{2}{|c|}{ Sreepur $(\mathrm{n}=10)$} & \multicolumn{2}{c|}{ Mithapukur $(\mathrm{n}=10)$} & \multirow{2}{*}{ Total } \\
\cline { 2 - 5 } & Small traders & Large traders & Small traders & Large traders & \\
\hline \hline Lack of sufficient funds & 72.2 & 63.1 & 89.0 & 67.5 & 72.9 \\
Lack of clients & 23.5 & 15.1 & 57.8 & & 24.1 \\
Lack of means of transport & 55.9 & 45.8 & 48.0 & 56.9 & 51.7 \\
Poor storage facilities & 46.6 & 40.1 & 35.0 & 53.0 & 43.7 \\
Milling problem & & 90.5 & & 88.0 & 44.6 \\
Lack of market information & 39.0 & 58.2 & 44.0 & 42.0 & 45.8 \\
High marketing cost & 27.6 & 36.0 & 33.0 & 35.0 & 32.9 \\
Lack of market facilities & 35.4 & 28.6 & 38.0 & 25.0 & 31.8 \\
High marketing tolls & 31.0 & 24.9 & 29.0 & 20.0 & 26.2 \\
\hline
\end{tabular}

Source: Field survey data (2007)

Inadequate access to funds implies that traders can not expand their operations. Discussions with traders indicated that access to formal credit was limited. Access to the means of transport is essential to the private traders' operations. Traders' lack of transport facilities was due to poor state of roads. One of the major assumptions underlying market liberalization is that the private sector will take advantage of the price variations seasonally. The interesting point here is that most of the traders do not store their crops for a long time. This behavior was attributed to the lack of storage facilities coupled with the high storage costs involved, due to rentals and spoilage of the crop.

Traders suggested that government set easy terms and conditions to lend money to traders so that they can easily borrow money from banks. They also suggested that more funds should be allocated in rural areas for building new roads and bridges and maintaining infrastructure to improve the rural road network.

\section{Conclusion}

Advocates of liberalization implicitly assumed that market signals would make farmers adopt the production of crops in which their areas had a comparative advantage relative to other parts of the country. However the structure of agricultural production presented a powerful lock-in factor that made farmers unwilling to change quickly. This was worsened by the poor human capital characteristics prevailing in the rural areas, making it difficult for the small farmers to receive and 
process new information on production technologies very quickly and start growing other crops. The lack of market integration in Bangladesh, as in many developing countries is due to a number of bottlenecks related to non-price factors. These were identified as lack of credit facilities, storage and transportation and poor road infrastructure. For the rice markets to be fully integrated in Bangladesh the government is advised to intensify its efforts at providing an enabling environment that will encourage private participation in not only rice markets but also other agricultural products, storage, transportation, and input and credit provision. This would involve the provision of effective price information, storage, transportation and input and credit provision.

The provision of an effective market information system is vital for the transmission of prices and efficiency of the marketing system. Although an attempt has been made by the Bangladesh government to put an information system in place, access to market information by farmers and traders especially in rural remote areas is limited. The government needs to take measures that strengthen the agricultural price and marketing information system targeted at both farmers and traders.

The government has tried to provide price information for a number of crops through the weekly bulletins and the radio; however, this information is not easily accessible to farmers due to a number of reasons. First with regard to the bulletins, most farmers are not able to interpret this information because they are illiterate (World Bank, 1999). Second, even if the information is disseminated through the radio, many farmers do not own radios and besides most are too busy in their fields or with other activities to have the time to listen to the radio. To overcome this, the weekly bulletins are interpreted into local languages and that contain price information specific to demand supply situations in their respective areas.

Government can also foster further private participation and market integration by improving the road and storage infrastructure. Improvement of road and transport infrastructure can be achieved through increased investment in not only road repair maintenance but also in the construction of new roads and better bridges particularly in those areas that get cut off during the rainy season. There is also need to invest in storage facilities to encourage traders and farmers to store. In particular farmers should be assisted to build on-farm storage facilities to take advantage of seasonal price variations. All of this leads to the conclusion that efficiency of the rice marketing system in Bangladesh will improved a lot if access to credit for farmers and traders is improved. The lack of credit has hindered private traders' investment in storage, transportation and expansion of their operations. Farmers have also been hindered from improving their productivity due to lack of funds to purchase fertilizer, diesel and other inputs. In general credit has hindered both farmers and traders from engaging in speculative storage.

To achieve market integration in the rice markets and indeed in other agricultural markets in Bangladesh, the government needs to continue providing an enabling environment for the emerging private sector. As Due (1993) correctly points out, this means a continued commitment to creating a competitive, market oriented economy, with a positive investment climate, wellfunctioning capita markets and ensuring a growing economy. 


\section{References}

BBS 2005. The statistical yearbook of Bangladesh. Bangladesh Bureau of Statistics, Planning Division, Ministry of Planning, Government of the Peoples' Republic of Bangladesh. Dhaka, Bangladesh.

BBS. 2006. The statistical yearbook of Bangladesh. Bangladesh Bureau of Statistics, Planning Division, Ministry of Planning, Government of the Peoples' Republic of Bangladesh. Dhaka, Bangladesh.

BBS. 2007. Report of the household income and expenditure survey 2005. Bangladesh Bureau of Statistics, Planning Division, Ministry of Planning, Government of the Peoples' Republic of Bangladesh. Dhaka, Bangladesh.

Chowdhury N., N. Farid, and D. Roy. 2006. Food policy liberalization in Bangladesh: how the government and the markets delivered? MTID Discussion Paper No. 92. International Food Policy Research Institute. Washington, D.C.

Dorosh, P. and Q. Shahabuddin. 2002. Rice price stabilization in Bangladesh: an analysis of policy options. MSSD Discussion Paper No. 46. International Food Policy Research Institute, Washington D.C.

Garrett, J. and S. Chowdhury. 2004. Urban-rural links and transformation in Bangladesh: a review of the issues. CARE Discussion Paper. International Food Policy Research Institute. CARE-Bangladesh.

GOB. 2000. Report of the task force on comprehensive food security policy for Bangladesh. Government of the Peoples' Republic of Bangladesh. Bangladesh.

Goletti, F. 1994. The changing public role in a rice economy approaching self-sufficiency: the case of Bangladesh. Research Report 98. International Food Policy Research Institute, Washington, D.C.

Handbook of Agricultural Statistics. 2005. Bangladesh Bureau of Statistics, Planning Division, Ministry of Planning, Government of the Peoples' Republic of Bangladesh. Dhaka, Bangladesh. (http://www.moa.gov.bd/statistics/statistics.htm\#11), Last consulted 11/5/2007.

Hossain, M.I. 1999. A study on price spreads of major crops in selected markets of Bangladesh. M.

S. Thesis. Department of cooperation and marketing, Bangladesh Agricultural University, Mymensingh.

Tasnoova, Shuraya and Izumi Iwamoto. 2006. Kataribhog rice marketing system in Dinajpur district, Bangladesh. Mem Fac Agric Kagoshima Univ . 41: 19-50.

World Bank. 1999. Bangladesh: Agricultural sector strategies: issues and options. Washington D.C. 